\title{
How reversible is sea ice loss?
}

\author{
J. K. Ridley, J. A. Lowe, and H. T. Hewitt \\ Met Office, FitzRoy Road, Exeter, EX1 3PB, UK \\ Correspondence to: J. K. Ridley (jeff.ridley@metoffice.gov.uk)
}

Received: 29 July 2011 - Published in The Cryosphere Discuss.: 8 September 2011

Revised: 24 January 2012 - Accepted: 31 January 2012 - Published: 13 February 2012

\begin{abstract}
It is well accepted that increasing atmospheric $\mathrm{CO}_{2}$ results in global warming, leading to a decline in polar sea ice area. Here, the specific question of whether there is a tipping point in the sea ice cover is investigated. The global climate model HadCM3 is used to map the trajectory of sea ice area under idealised scenarios. The atmospheric $\mathrm{CO}_{2}$ is first ramped up to four times pre-industrial levels $\left(4 \times \mathrm{CO}_{2}\right)$, then ramped down to pre-industrial levels. We also examine the impact of stabilising climate at $4 \times \mathrm{CO}_{2}$ prior to ramping $\mathrm{CO}_{2}$ down to pre-industrial levels. Against global mean temperature, Arctic sea ice area is reversible, while the Antarctic sea ice shows some asymmetric behaviour - its rate of change slower, with falling temperatures, than its rate of change with rising temperatures. However, we show that the asymmetric behaviour is driven by hemispherical differences in temperature change between transient and stabilisation periods. We find no irreversible behaviour in the sea ice cover.
\end{abstract}

\section{Introduction}

The decline of Arctic sea ice in response to increasing concentrations of atmospheric $\mathrm{CO}_{2}$ has been much studied in climate models (Gregory et al., 2002; Winton, 2006; Holland et al., 2006; Ridley et al., 2007; Wang and Overland, 2009). Typically these show an approximately linear relationship between the decrease in extent of the Arctic sea ice in September and global average near-surface warming, although the constant of proportionality remains uncertain. Attempts to constrain the models using observations provide one means of narrowing this uncertainty (e.g. Boe et al., 2010). Most climate models do not show a clear abrupt acceleration of the rate of summer sea ice loss with global temperature rise. However, in HadCM3, while the demise of the Arctic annual mean sea ice varies linearly with temper- ature over a wide range of values, the winter ice does show a more rapid decline as an apparent temperature threshold is reached. This only occurs after a large fraction of the winter ice has already been lost above a global warming of around $7{ }^{\circ} \mathrm{C}$ (Ridley et al., 2008).

For the Antarctic, the sea ice extent has seen a slight increase since the 1970s (Turner et al., 2009), and although climate models can simulate this, the model uncertainty is greater than in the Arctic (Arzel et al., 2006). The pattern of sea ice change is related to the southern annular mode (Lefebvre et al., 2004) and the history of changes in the Southern Ocean (Goosse and Renssen, 2005).

These studies of Arctic and Antarctic sea ice loss raise the following question: if the global average or local warming is reversed, will the sea ice cover quickly return to its initial state (reversibility)? The answer has implications for how sea ice is viewed in discussions of dangerous climate change and for policies to avoid them.

Schroder and Connolley (2007) performed experiments for both the Southern and Northern Hemisphere sea ice using the HadCM3 climate model in which the ocean mixed layer was adjusted to represent that in ice free regions. They found that the sea ice recovered fully within $15 \mathrm{yr}$. More recently, Tietsche et al. (2011) showed that the instantaneous removal of Arctic sea ice in a climate model, from various periods during its decline, results in its rapid regrowth to the state prior to its removal. A different experimental approach is to force the climate in a reversible manner, ramping $\mathrm{CO}_{2}$ up to some threshold then back down to the initial state (Armour et al., 2011). Observations of the transient sea ice behaviour throughout such forcing will determine the reversible behaviour. Taken together, the experiments suggest that there is no threshold, either in sea ice extent or global average warming, which leads to sea ice loss becoming irreversible in climate models. 


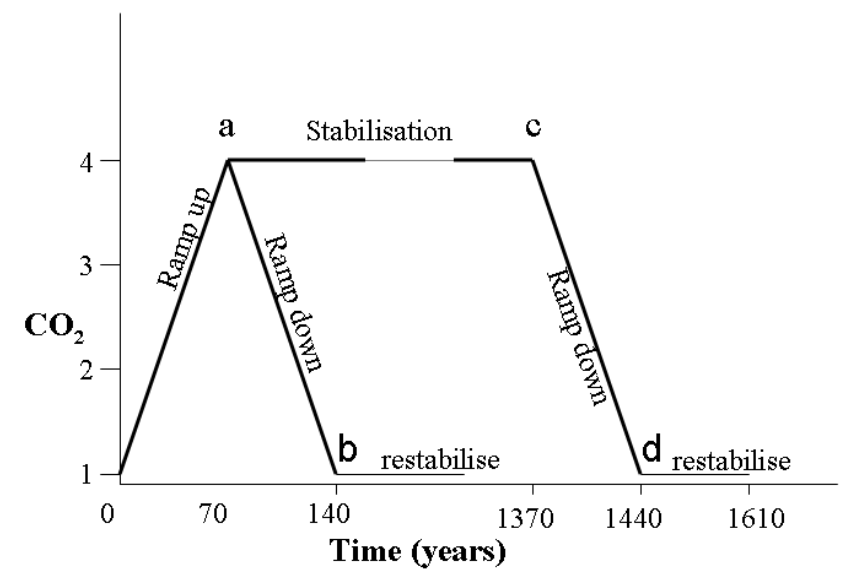

Fig. 1. The prescribed $\mathrm{CO}_{2}$ trajectories used in the HadCM3 experiments. Trajectory $0-a-b$ represents the "fast" scenario. Trajectory 0 -a-c-d represents the "slow" scenario.

In this study we examine the issue of irreversibility using the experimental approach of Armour et al. (2011). If the sea ice loss is found not to be irreversible, then we will extend our analysis to estimate the magnitude of any lag in the recovery of sea ice behind changes in the climate forcing. Our approach involves ramping up the atmospheric $\mathrm{CO}_{2}$ concentration from pre-industrial levels (280 ppm), then bringing it back down again either immediately, similar to that of Armour et al. (2011), or after a period of stabilisation. Although the rates of $\mathrm{CO}_{2}$ change are idealised in our study, the rates of $\mathrm{CO}_{2}$ increase are not inconceivable when compared to the range of available policy-relevant emission scenarios (Nakićenović et al., 2000). The rates of $\mathrm{CO}_{2}$ decline are more speculative, but an increasing number of studies (e.g. Arora et al., 2011) envisage negative carbon emissions late in the 21 st century from burning of biofuels with carbon capture and storage (Matthews, 2008).

\section{Method}

The coupled ocean-atmosphere general circulation model HadCM3 is used in this study. The sea ice model in HadCM3 consists of a thermodynamic component with simple dynamics in which winds drive the ocean currents then advect the sea ice (Gordon et al., 2000). The ice advection scheme is simple in that ice velocities are set to zero if ice would be transported to a region of ice thicker than $4 \mathrm{~m}$. The model produces a reasonable simulation of Arctic sea ice change in response to climate forcing, although there is less skill for the Antarctic (Gregory et al., 2002).

Two simulations were conducted to map the possible trajectories of the ice area in response to $\mathrm{CO}_{2}$ induced global temperature change (Fig. 1). In both simulations the atmospheric $\mathrm{CO}_{2}$ concentration is initially increased at a rate of $2 \%$ a year from preindustrial concentrations for $70 \mathrm{yr}$ until a
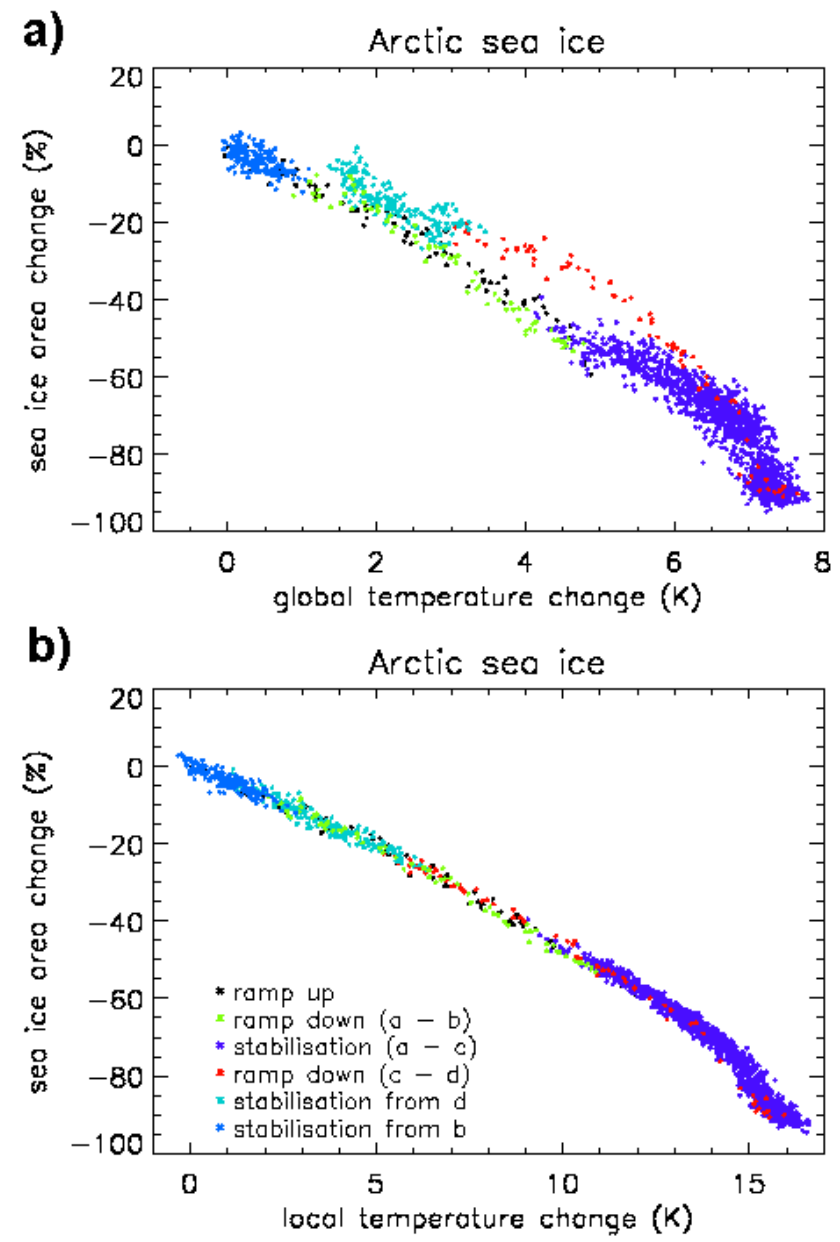

Fig. 2. The sensitivity of Arctic sea ice area change to (a) global temperature change and (b) local temperature change. Colours refer to the $\mathrm{CO}_{2}$ trajectory markers specified in Fig. 1.

$\mathrm{CO}_{2}$ concentration four times preindustrial is reached (point "a" on Fig. 1). The first experiment then immediately ramps down $\mathrm{CO}_{2}$ at $2 \%$ a year until pre-industrial concentrations are reached (point "b"), followed by a period of stabilisation with $\mathrm{CO}_{2}$ pre-industrial concentrations for $160 \mathrm{yr}$. We will call this the "fast" scenario. The second, "slow" scenario, stabilises concentrations at $4 \times \mathrm{CO}_{2}$ for $1000 \mathrm{yr}$ (point "c"), and then ramps down $\mathrm{CO}_{2}$ at $2 \%$ a year for $70 \mathrm{yr}$ (point "d") followed by $160 \mathrm{yr}$ with $\mathrm{CO}_{2}$ at pre-industrial levels. The two scenarios, fast and slow, are considered idealised extremes which bracket the range of policy-relevant scenarios.

\section{Results and discussion}

\subsection{Arctic ice extent}

Changes in the annual mean Arctic ice area (Fig. 2a) are approximately linear with global temperature change (Ridley et al., 2007; Winton, 2011). During the atmospheric $\mathrm{CO}_{2}$ 
ramp-up the Arctic becomes ice free in September following a global temperature rise of approximately $4{ }^{\circ} \mathrm{C}$, and is icefree year round following a global temperature rise of $7.5^{\circ} \mathrm{C}$ - a global temperature only achieved during the long stabilisation period at $4 \times \mathrm{CO}_{2}$. There is a slight change in the gradient once the summer ice is lost, and winter ice loss accelerates towards the end of its demise. With the immediate ramp-down from point " $a$ " the ice area is found to be entirely reversible with global mean temperature, and there is no evidence of the sea ice recovery lagging behind the global temperature decline. After a sustained period of stabilisation (point "c"), the $\mathrm{CO}_{2}$ ramp-down also sees the winter ice recover as global temperatures fall. Indeed there is some evidence of the ice area recovering slightly more rapidly than in the "fast" scenario.

The sea ice area change is plotted against the regional temperature change (Fig. 2b), defined as the average $1.5 \mathrm{~m}$ air temperature north of $70^{\circ} \mathrm{N}$. The scatter is reduced and the simulation of ice area is entirely reversible with this measure of local temperature change. The "slow" scenario lag in Fig. 2a is absent in Fig. 2b, indicating that the effect is due to the regional ocean cooling faster than the global ocean, rather than being an innate feature of the sea ice properties. It also suggests that any changes that occur in the ocean vertical structure, as a consequence of heat uptake, do not influence the surface heat fluxes and the associated sea ice response.

\subsection{Antarctic sea ice extent}

In the Antarctic the return trajectory (Fig. 3), points a-b, the ice cover is reversible if the atmospheric $\mathrm{CO}_{2}$ concentration and temperatures are reduced quickly after the $\mathrm{CO}_{2}$ peak (Fig. 3a). However, on stabilisation at $4 \times \mathrm{CO}_{2}$ the temperature sensitivity of the ice area, although still linear, is noticeably increased. The ice sensitivity to temperature changes is different again during the $\mathrm{CO}_{2}$ ramp-down, points $\mathrm{c}-\mathrm{d}$, being lower than during either the ramp-up or stabilisation period.

When the ice area change is depicted as a function of regional temperature (Fig. 3b), defined as the average $1.5 \mathrm{~m}$ air temperature between 75 and $55^{\circ} \mathrm{S}$, the ice response is more similar to the Arctic case (Fig. 2b), being almost reversible in the slow scenario. Only a slight deviation in ice area against temperature is seen between the ramp-up and ramp-down pathways. Such a deviation, not investigated here, may be due to differences in the modelled southern annular mode and its impact on the sea ice spatial coverage (Lefebvre et al., 2004).

\subsection{Asymmetry in the hemispheric temperature response}

The radiative forcing in HadCM3 first results in a temperature anomaly in the ocean mixed layer system which gradually spreads to the deep ocean, a process noted by Hansen et al. (1984). High latitudes are important for deep ocean heat
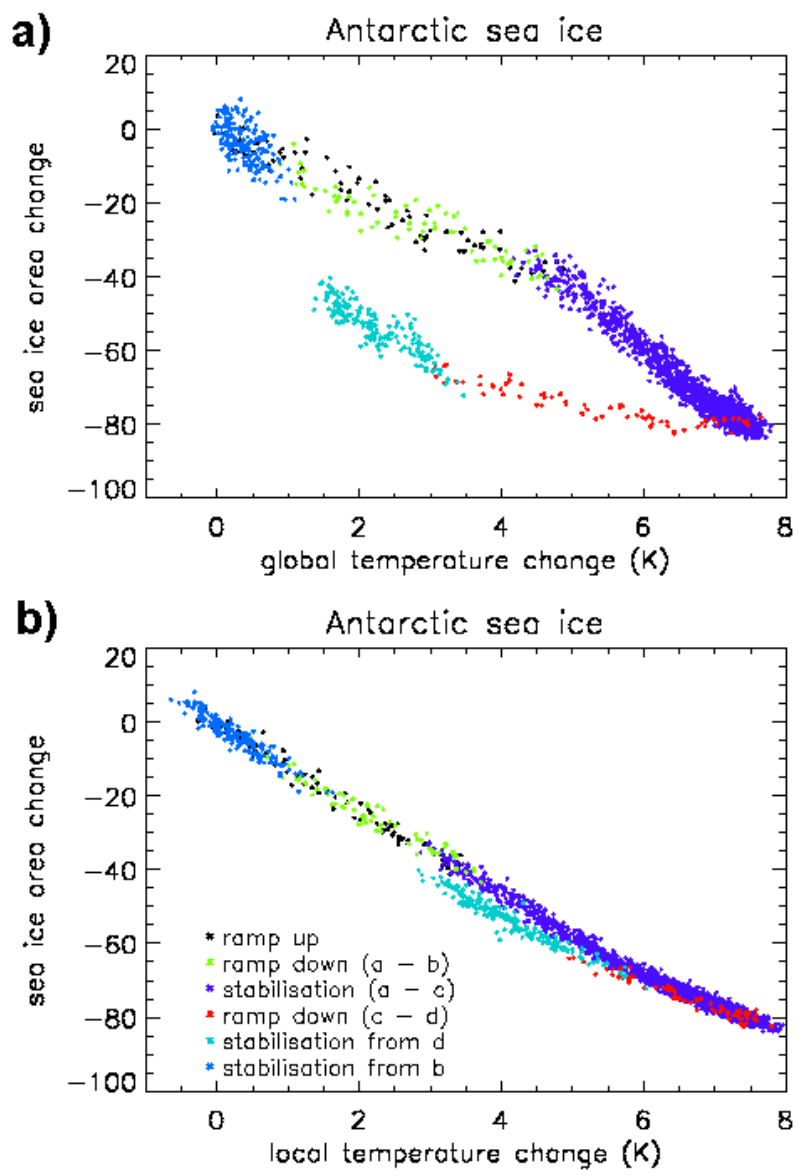

Fig. 3. The sensitivity of Antarctic sea ice area change to (a) global temperature change and (b) local temperature change. Colours refer to the $\mathrm{CO}_{2}$ trajectory markers specified in Fig. 1.

uptake, as the characteristic deep vertical mixing of these regions provides access to store heat in the deep ocean (Russell et al., 2006). The deeper mixed layers at high southern latitudes are associated with enhanced deep ocean heat uptake in the transient response to $\mathrm{CO}_{2}$ forcing, and consequently lead to regionally lesser surface warming (Boe et al., 2009; Winton et al., 2010)

In the HadCM3 transient climate simulations, atmospheric $\mathrm{CO}_{2}$ ramp-up and ramp-down, the Northern Hemisphere $1.5 \mathrm{~m}$ air temperature changes 1.6 times faster than that of the Southern Hemisphere (Fig. 4). This is a consequence of a combination of enhanced Southern Ocean heat uptake and land-sea temperature contrast (Joshi et al., 2008; Dong et al., 2009), in that land warms/cools faster than ocean, and the bias in the global distribution of land to the Northern Hemisphere. During the period of stabilisation at $4 \times \mathrm{CO}_{2}$, as the climate system approaches equilibrium, the balance is reversed and the Southern Hemisphere warms at a rate of 1.2 times that of the Northern Hemisphere (Fig. 4). The transition between the faster warming northern and Southern Hemispheres occurs over a period of $\sim 30 \mathrm{yr}$. 


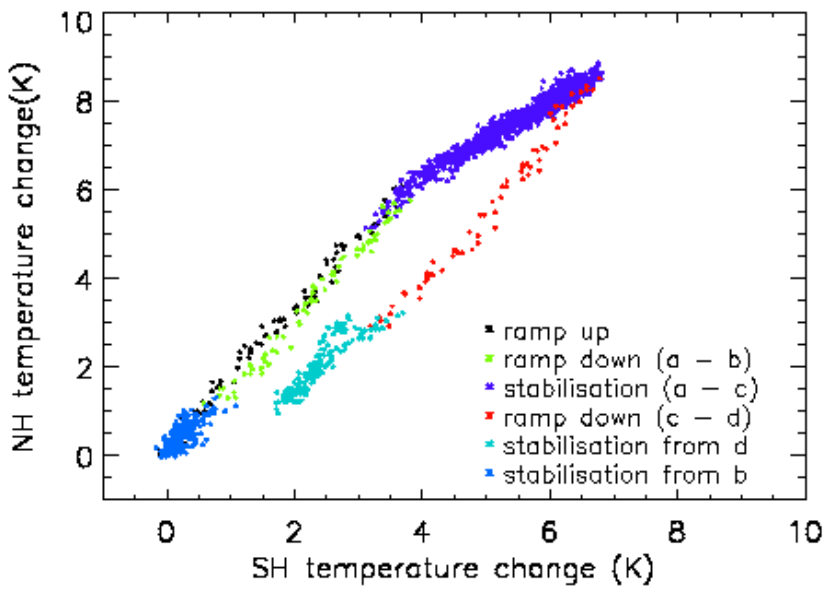

Fig. 4. The hysteresis in the hemispheric $(\mathrm{NH}=$ Northern Hemisphere, $\mathrm{SH}=$ Southern Hemisphere) near-surface air temperature. Stages "a" to "d" are as depicted in Fig. 1.

Throughout the $4 \times \mathrm{CO}_{2}$ stabilisation period (points "a" to "c") the intermediate waters of the Southern Ocean take up heat in summer. However, the modelled mixed layer deepens in winter such that a portion of the heat from below is entrained into the mixed layer, resulting in warmer winter air temperatures. Figure 5 shows the evolution of the Southern Ocean temperature structure. Over the fast scenario (Fig. 5a) an imbalance of surface fluxes leads to ocean heat uptake, resulting in a warming at $\sim 400 \mathrm{~m}$ depth. The heat diffuses both into the deep ocean and upwards, where it is entrained by the mixed layer. The entrainment is evident after the peak in the ramp-up of $\mathrm{CO}_{2}$ at (a), as the sea ice minimum extent lags peak $\mathrm{CO}_{2}$ by $\sim 12 \mathrm{yr}$ while the heat anomaly is eroded. The full recovery of the sea ice cover on return to $1 \times \mathrm{CO}_{2}$ (point "b") is similarly delayed. During the "slow" scenario (Fig. 5b) and stabilisation at $4 \times \mathrm{CO}_{2}$ the ocean heat uptake is considerable, and the temperature anomaly at $400 \mathrm{~m}$ depth grows to $4{ }^{\circ} \mathrm{C}$. As a consequence of the heat release, the ocean surface remains $\sim 2{ }^{\circ} \mathrm{C}$ warmer even after a $160 \mathrm{yr}$ period of stabilisation at $1 \times \mathrm{CO}_{2}$. Warming of the deep ocean continues to the end of the simulation. Stouffer (2004) finds that in the Southern Hemisphere, the GCM surface response time is slightly faster when cooling due to a decreasing stability, but that this is still on the order of $1000 \mathrm{yr}$. The Northern Hemisphere surface response time scales are much faster than either the warming or cooling Southern Hemisphere surface response time scales. Because of the depth of the Southern Ocean, the heat is mixed through deeper and deeper layers of the ocean, leading to smaller fractions of the total response near the ocean surface (Stouffer, 2004).

The Arctic Ocean structure is defined in HadCM3 by the strong halocline at about $120 \mathrm{~m}$ depth. Throughout the simulations a freshening of the surface waters maintains the halocline, with no evidence that it will be breached through enhanced vertical mixing. The Arctic warms at the surface and

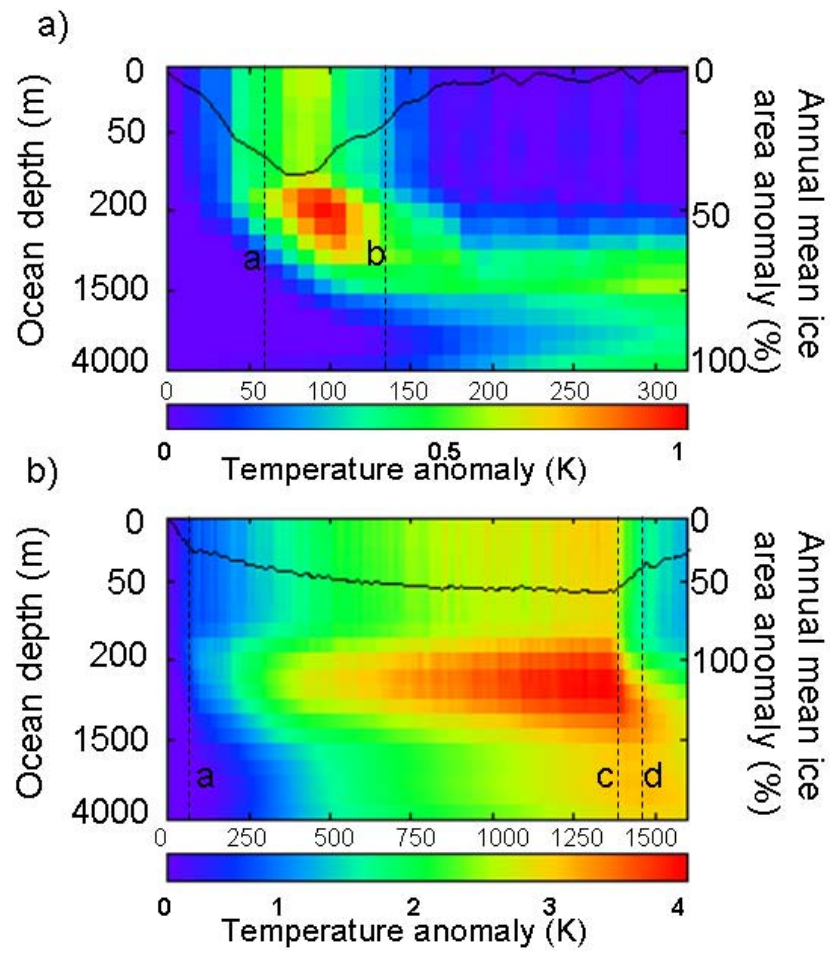

Fig. 5. The Southern Ocean potential temperature anomaly, as a function of ocean depth (averaged between 75 and $55^{\circ} \mathrm{S}$ ), in simulated time (years) for the fast scenario (top) and the slow scenario (bottom). The $\mathrm{x}$-axis is simulation years. At the top is the change in the associated anomaly in Antarctic sea ice area. Note that the ocean depth axis has is a non-linear scale. Labels are as depicted in Fig. 1.

through advection at $300-700 \mathrm{~m}$ depth, but the two water masses remain decoupled and the intermediate waters have no discernable impact on the sea ice cover. Consequently, the Antarctic sea ice recovery lags behind that in the Arctic.

\section{Conclusions}

We have conducted idealised simulations with the climate model HadCM3, in which the atmospheric concentration of $\mathrm{CO}_{2}$ is first ramped up from pre-industrial to four times preindustrial levels. In one experiment the $\mathrm{CO}_{2}$ is immediately ramped back down to, and then stabilised at, pre-industrial levels. In a second experiment the $\mathrm{CO}_{2}$ is stabilised at four times pre-industrial levels for $1000 \mathrm{yr}$ before ramping down to pre-industrial levels.

We have investigated the polar climate response to climatic changes arising from the two $\mathrm{CO}_{2}$ scenarios. It is clear that the sea ice in the fast scenario responds linearly to global mean temperature almost equally for the ramp-up and rampdown of $\mathrm{CO}_{2}$. However, in the slow scenario, the deep waters of the Southern Ocean become warmer and more saline over centennial timescales. The timescale for GCM global oceans 
to reach $70 \%$ of their equilibrium temperature is $\sim 1000 \mathrm{yr}$ with the Southern Ocean taking longer (Stouffer, 2004). The dominant source of the oceanic heat is increased surface heat uptake as sea ice declines. The heat is stored temporarily in intermediate waters at $\sim 400 \mathrm{~m}$ depth before eventually being transferred back to the surface and to the deep ocean. The intermediate waters become a store of heat that can be accessed through mixed layer entrainment as the climate cools, slowing the rate of recovery of the sea ice in some regions of Antarctica. In the Arctic, a surface freshening reduces the mixed layer depth and prevents a surface release of the stored heat before it is lost to the deeper ocean.

An analysis of the climate sensitivity of the sea ice cover shows that against global mean temperature rise there is apparently a lag in the recovery of lost sea ice, which is especially noticeable in the Antarctic. When the same analysis is conducted against local temperatures, no lag is evident. The apparent sea ice lag arises because the Southern Hemisphere temperatures lag behind those in the North during the rampup and immediate ramp-down experiments. However, during the stabilisation at $4 \times \mathrm{CO}_{2}$ the southern and northern temperatures are close to equalising. The ramp-down in the slow scenario does not start from the same state as the ramp-down in the fast scenario, and a hemispheric temperature "hysteresis" is created. The temperature- sea ice trajectory during the short stabilisation period (point "d" onwards) is towards the initial state, and a sufficiently long period should see the loop completed. Since the "hysteresis" is a function of the rate of ocean heat uptake and release, we would expect differences between climate models which affect transient climate sensitivity (Raper et al., 2002). Although the use of global temperature as a reference for sea ice is applicable in the assessment of transient climate sea ice sensitivity (Gregory et al., 2002; Ridley et al., 2007), it may not be suitable in long simulations when ocean heat uptake is significant. The inter-hemispheric temperature loop feeds through to an effect on hemispheric climate processes such as those related to sea ice.

Thus, we find no clear evidence of a threshold of irreversibility in the sea ice, but Antarctic sea ice does lag behind global temperature during a return to lower temperatures after a period of extended $\mathrm{CO}_{2}$ stabilisation. However, the simulation is not sufficiently long to close the temperature - ice area loop, and a bistability cannot be definitively ruled out. This result is similar to that of Armour et al. (2011), who find reversible behaviour in the NCAR CCSM3 climate model with a simple ramp-up then ramp-down experiment. Our result complements that of Armour et al. (2011), not only by showing that sea ice reversibility is robust across more than one type of sea ice sub-model in different climate models, but also by extending the period of stabilisation at high levels of $\mathrm{CO}_{2}$, showing that sea ice area in both hemispheres is reversible.
Acknowledgements. This work was supported by the Joint DECC/Defra Met Office Hadley Centre Climate Programme (GA01101).

Edited by: W. Lipscomb

\section{References}

Armour, K. C., Eisenman, I., Blanchard-Wrigglesworth, E., McCusker, K. E., and Bitz, C. M.: The reversibility of sea ice loss in a state-of-the-art climate model, Geophys. Res. Lett., 38, L16705, doi:10.1029/2011GL048739, 2011.

Arora, V. K., Scinocca, J. F., Boer, G. J., Christian, J. R., Denman, K. L., Flato, G. M., Kharin, V. V., Lee, W. G., and Merryfield, W. J.: Carbon emission limits required to satisfy future representative concentration pathways of greenhouse gases, Geophys. Res. Lett., 38, L05805, doi:10.1029/2010GL046270, 2011.

Arzel, O., Fichefet, T., and Goosse, H.: Sea ice evolution over the 20th and 21st centuries as simulated by current AOGCMs, Ocean Model., 12, 401-415, 2006.

Boe, J., Hall, A., and Qu, X.: Deep ocean heat uptake as a major source of spread in transient climate change simulations, Geophys. Res. Lett., 36, L22701, doi:10.1029/2009GL040845, 2009.

Boe, J. L., Hall, A., and Qu, X.: Sources of spread in simulations of Arctic sea ice loss over the twenty-first century, Climatic Change, 99, 637-645, 2010.

Dong, B., Gregory, J. M., and Sutton, R. T.: Understanding LandSea Warming Contrast in Response to Increasing Greenhouse Gases. Part I: Transient Adjustment, J. Climate, 22, 3079-3097, doi:10.1175/2009JCLI2652.1, 2009.

Goosse, H. and Renssen, H.: A simulated reduction in Antarctic sea-ice area since 1750: implications of the long memory of the ocean, Int. J. Climatol., 25, 569-579, doi:10.1002/joc.1139, 2005.

Gordon, C., Cooper, C., Senior, C. A., Banks, H., Gregory, J. M., Johns, T. C., Mitchell, J. F. B., and Wood, R. A.: The simulation of SST, sea ice extents and ocean heat transports in a version of the Hadley Centre coupled model without flux adjustments, Clim. Dynam., 16, 147-168, 2000.

Gregory, J. M., Stott, P. A., Cresswell, D. J., Rayner, N. A., Gordon, C., and Sexton, D. M. H.: Recent and future changes in Arctic sea ice simulated by the HadCM3 AOGCM, Geophys. Res. Lett., 29, 2175, doi:10.1029/2001GL014575, 2002.

Hansen, J., Lacis, A., Rind, D., Russell, G., Stone, P., Fung, I., Ruedy, R., and Lerner, J.: Climate sensitivity: Analysis of feedback mechanisms, in: Climate Processes and Climate Sensitivity, AGU Geophysical Monograph 29, Maurice Ewing Vol. 5, edited by: Hansen, J. E. and Takahashi, T., American Geophysical Union, 130-163, 1984.

Holland, M. M., Bitz, C. M., and Tremblay, B.: Future abrupt reductions in the summer Arctic sea ice, Geophys. Res. Lett., 33, L23503, doi:10.1029/2006GL028024, 2006.

Joshi, M. M., Gregory, J. M., Webb, M. J., Sexton, D. M. H., and Johns, T. C.: Mechanisms for the land/sea warming contrast exhibited by simulations of climate change, Clim. Dynam., 30, 455-465, doi:10.1007/s00382-007-0306-1, 2008.

Lefebvre, W., Goosse, H., Timmermann, R., and Fichefet, T.: Influence of the Southern Annular Mode on the sea ice-ocean system, 
J. Geophys. Res., 109, C09005, doi:10.1029/2004JC002403, 2004.

Mathews, J. A.: Carbon-negative biofuels, Energ. Policy, 36, 940945, 2008.

Nakićenović, N. and Swart, R. (Eds.): IPCC Special Report on Emissions Scenarios, Cambridge University Press, Cambridge, UK, 612 pp., 2000.

Raper, S. C. B., Gregory, J. M., and Stouffer, R. J.: The Role of Climate Sensitivity and Ocean Heat Uptake on AOGCM Transient Temperature Response, J. Climate, 15, 124-130, 2002.

Ridley, J., Lowe, J., Brierley, C., and Harris, G.: Uncertainty in the sensitivity of Arctic sea ice to global warming in a perturbed parameter climate model ensemble, Geophys. Res. Lett., 34, L19704, doi:10.1029/2007GL031209, 2007.

Ridley, J., Lowe, J., and Simonin, D.: The demise of Arctic sea ice during stabilisation at high greenhouse gas concentrations, Clim. Dynam., 30, 333-341, doi:10.1007/s00382-007-0291-4, 2008.

Russell, J. L., Dixon, K. W., Gnanadesikan, A., Stouffer, R. J., and Toggweiler, J. R.: The Southern Hemisphere westerlies in a warming world: Propping open the door to the deep ocean, J. Climate, 19, 6382-6390, 2006.

Schroder, D. and Connolley, W. M.: Impact of instantaneous sea ice removal in a coupled general circulation model, Geophys. Res. Lett., 34, L14502, doi:10.1029/2007GL030253, 2007.
Stouffer, R. J.: Time Scales of Climate Response, J. Climate, 17, 209-217, 2004.

Tietsche, S., Notz, D., Jungclaus, J. H., and Marotzke, J.: Recovery mechanisms of Arctic summer sea ice, Geophys. Res. Lett., 38, L02707, doi:10.1029/2010GL045698, 2011.

Turner, J., Comiso, J. C., Marshall, G. J., Lachlan-Cope, T. A., Bracegirdle, T., Maksym, T., Meredith, M. P., Wang, Z., and Orr, A.: Non-annular atmospheric circulation change induced by stratospheric ozone depletion and its role in the recent increase of Antarctic sea ice extent, Geophys. Res. Lett., 36, L08502, doi:10.1029/2009GL037524, 2009.

Wang, M. and Overland, J. E.: A sea ice free summer Arctic within 30 years?, Geophys. Res. Lett., 36, L07502, doi:10.1029/2009GL037820, 2009.

Winton, M.: Does the Arctic sea ice have a tipping point?, Geophys. Res. Lett., 33, L23504, doi:10.1029/2006GL028017, 2006.

Winton, M., Takahashi, K., and Held, I. M.: Importance of Ocean Heat Uptake Efficacy to Transient Climate Change, J. Climate, 23, 2333-2344, doi:10.1175/2009JCLI3139.1, 2010.

Winton, M.: Do Climate Models Underestimate the Sensitivity of Northern Hemisphere Sea Ice Cover?, J. Climate, 24, 39243934, doi:10.1175/2011JCLI4146.1, 2011. 